American Journal of Pharmaceutical Education 2017; 81 (7) Article 6695.

\title{
COMMENTARY
}

\section{Mentors and Lessons Learned}

\author{
Gayle A. Brazeau, PhD, a,b \\ ${ }^{a}$ University of New England, College of Pharmacy, Portland, Maine \\ ${ }^{\mathrm{b}}$ Editor, American Journal of Pharmaceutical Education, Alexandria, Virginia
}

The passing of important mentors and friends over the last two years is the inspiration for this commentary. It provided me with the opportunity to reflect on the mentors and friends who have provided me with the most precious gifts - time and caring - so that I could continue to grow and learn as a student, faculty member, administrator, and most importantly, as a thoughtful, conscientious, helpful and kind individual. The wide array of individuals that we all have as mentors and friends have provided us with many essential lessons that form the foundation of what we do each day in our various roles. This commentary will focus on those lessons from mentors (research advisors, committee members, senior faculty members and supervisors such as chairs, assistant/associate deans, and deans) who have guided me through my academic career to date. This is not to say that we have not learned and will continue to learn important lessons from our family and friends, but this reflection is focused on lessons that were reinforced by these mentors. I have been extremely fortunate to learn from these mentors and now attempt to pass this wisdom and knowledge on to other faculty and staff colleagues as well as the students at the undergraduate, graduate, and professional levels. This commentary will highlight six specific lessons that I am now trying to share with others when given the opportunity to serve as a mentor. The order of this list does not imply any ranking in terms of importance.

First, love what you do each day. We all bring talents, abilities and passions to our roles as pharmacy educators. One cannot judge one's activities and pathways by what others think is the only way to be successful. You must certainly decide your path using your intellect. Your journey should be guided by your heart and a sensible vision for what you consider to be the hallmarks of a successful academic career. If you find yourself at a stage where you are not enthusiastic about going to work each morning, you need to identify the disconnect and rectify your feelings in order to remain at your current institution or alternatively, you must consider other options.

Second, never believe that you know everything. One of the most important lessons I learned in graduate school was to be intellectually honest with myself as to what I know and what I do not know and to combine this honesty with a passion to never stop learning. The mentor who taught me this lesson made it very simple to remember. The day you believe you know everything is the day you know nothing and others will show you that you know nothing. Always be honest in what you do know, and more importantly, always be intellectually curious and willing to learn new ideas or reshape your thinking on current ideas.

Third, own your decisions and learn from them. Yes, we all must make decisions in any academic position and we hope we make those with the best knowledge in hand. However, even when one is unwilling to make a decision or is indecisive in their judgement, they have, in fact, actually rendered a decision. However, despite care in our decision-making process, some decisions may, in retrospect, have not been the best. It is often too easy for us to either beat ourselves up or blame others on the outcomes. This has been one of the hardest lessons I've learned through the years, but it does seem to get easier with aging (I am a firm believer that 60 is the new 40).

Fourth, there will be times when you do not achieve an immediate goal, but you must be resilient and bounce back. My research advisor was a highly successful scientist, but he always told us his stories or stories of even the best of the best researchers not having their grant funded or their manuscript being rejected or the best educators struggling with how to get their students/post-doctoral fellows to learn new ideas, concepts and/or skills through activities in the classroom, laboratory, or clinic. I learned from him and others that we are all allowed to be angry or mad at these rejections for a maximum period of 24 to 48 hours, after which we must resign ourselves to re-approach our projects and move them forward to the next step. One cannot be too stubborn as the next step in some circumstances could be to refocus our research or manuscripts. Everyone will experience rejection but those who stay resilient and positive will be successful over the long haul of an academic career.

Fifth, always challenge your students. It is essential as an educator to be tough but fair when interacting with students. We all remember the toughest individuals who 


\section{American Journal of Pharmaceutical Education 2017; 81 (7) Article 6695.}

challenged us (as students or post-doctoral fellows) during seminars, presentations, and defenses. These faculty did this with the philosophical foresight that it is better to face these situations in our home department or institution than this happening to us external of our own academic bubble. In a recent visit with a former graduate student, I heard the voice of my thesis advisor come back when this individual reminded me of how I would tell him that I was always going to be tough on him during his seminars and other presentations as this would prepare him for the future when he was presenting to colleagues outside the department and college.

Sixth, remember that success is based upon "we" not "I." At all levels of an academic career, those who are successful always acknowledge that they did not do it alone. It was the diligent and dedicated work of others combined with the sacrifices of others (often family and friends) that enabled them to relentlessly and passionately pursue success as educators, researchers, and clinicians. As part of the "we," it is essential to be a good citizen and support your colleagues and students in your division/department, college, university, and profession. Your commitment to follow through on projects when either working individually or in collaboration with others is the foundation for developing consistent and long-term success. We will have times in our academic career where we must overcome our pride and ask for assistance and learn and grow from the knowledge and advice of others. There will also be other times when we must be willing to provide our time and assistance to others when they are having challenging times. The "we" is the essential to what are the most successful communities of educators, researchers, clinicians, staff, and students.

These lessons I learned from my mentors further emphasized the great advantage and privilege of having an academic career. I believe this advantage and privilege is succinctly articulated by the words of Henry Ford on learning, age, and life - "Anyone who stops learning is old, whether at 20 or 80 . Anyone who keeps learning stays young. The greatest thing in life is to keep your mind young." I will always be thankful to those mentors who have taught me these important lessons. Furthermore, I look forward to future mentors who will continue to provide important lessons that will enable my ongoing learning and keep my mind young. 